\title{
Menopause in Central America: attitudes, symptoms and treatment
}

ARTICLE in MATURITAS · MAY 2009

Impact Factor: $2.94 \cdot$ DOI: 10.1016/S0378-5122(09)70448-7

READS

34

6 AUTHORS, INCLUDING:

\section{Gail Mahady}

University of Illinois at Chicago

131 PUBLICATIONS 2,077 CITATIONS

SEE PROFILE

Armando Caceres

University of San Carlos of Guatemala 108 PUBLICATIONS 2,200 CITATIONS

SEE PROFILE
Alice L. Perez

University of Costa Rica

42 PUBLICATIONS 633 CITATIONS

SEE PROFILE

Joanna Michel

University of Illinois at Chicago

23 PUBLICATIONS 87 CITATIONS

SEE PROFILE 
443

MENOPAUSE IN CENTRAL AMERICA: ATTITUDES, SYMPTOMS AND TREATMENT

$\underline{G . ~ M a h a d y ~}^{1}$, A. Perez ${ }^{2}$, A. Caceres ${ }^{3}$, T. Locklear $^{1}$, B. Doyle ${ }^{4}$, J. Michel $^{5}$. ${ }^{1}$ University of Illinois at Chicago, Pharmacy Practice, Chicago, United States; ${ }^{2}$ University of Costa Rica, CIPRONA, San Jose, Costa Rica; ${ }^{3}$ University of San Carlos, Guatemala City, Guatemala; ${ }^{4}$ University of Illinois at Chicago, Medicine, Chicago, United States; ${ }^{5}$ University of Illinois at Chicago, Public Health, Chicago, United States

Objectives: To investigate the attitudes and symptoms associated with the menopausal transition in Guatemalan and Costa Rican women and the therapies used to treat these symptoms.

Methods: As part of an NIH funded project, interviews of women, midwives, healers and medical personnel were performed. Plants used to treat menopause were collected in Guatemala and Costa Rica, extracted and tested.

Results: Women living in Central America have a more positive attitude toward menopause that their U.S. counterparts. While women in Guatemala have slightly fewer symptoms, women in Costa Rica have menopausal symptoms similar to that observed in U.S. women. However, neither women from Guatemala nor Costa Rica use HRT extensively and use herbal products instead to treat the symptoms associated with menopause. Plant species used as symptomatic treatment were collected and tested for potential biological activities. Many of the herbal remedies were active in multiple bioassays, suggesting a pleotropic and plausible mechanism of action for the treatment of anxiety, depression, vasomotor symptoms associated with the menopausal transition.

Conclusions: Women in Central American countries have similar symptoms during menopause as their U.S, counterparts but have a more positive outlook on the transition, as it marks an end to the reproductive years and allows for more sexual freedom. These women however, do not use HRT to any great extent, but opt for more natural therapies such as herbal medicines and massage. Many of the herbal products used appear to have a plausible mechanism of action.

Keywords: Menopause, Guatemala, Costa Rica, herbal, symptoms, vasomotor.

\section{4}

\section{FREQUENCY AND TREATMENT OF MENORRHAGIA}

A. Daneva-Markova. University Clinic of Obsterics and Gynecology, Clinic of Obsterics and Gynecology, Skopje, Macedonia, the Former Yugoslav Republic of

Objectives: Our aim was to find the best way in treating women who suffer from prologed and heavy menstrual bleeding in various age groups. Methods: We retrospectively analysed patients who had that problem in period of two years, we compared two groups by different causes: ovarian dysfunction on one side and some organic disease (myoma, polypus, inflammation). We also compared frequency in different age and coincidence with postoperative treatment with Th. Tamoxifen, and their treatment.

Results: There were 140 women with abnormal bleeding from uerus, 55 of them had menorrhagia (39\%). Among them 16 (31\%) were between 18-45 years old, $35(61 \%)$ between $45-50$, and $9(8 \%)$ over 50 years. Organic cause- $28(46 \%)$ patients, $5(20 \%)$ polypus cervicalis, $10(25 \%)$ polypus endometrialis, 12 (38\%) myoma uteri and 3 (14\%) inflammation. The rest of them, 30 patients had ovarian dysfunction and most of them belong to group between $45-50$ years, 52 patients had a heavy bleeding and we did curettage explorative, in 11 we found association with postoperative treatment with Th. Tamoxifen.And 16 patients were treated with medicament 9 gestagens, ergometrin. Connected with cause of bleeding as well s with the age we used different Therapy. 9 oral contraceptives, 10 with gestagenes, 8 operated, IUD with gestagen to 17 women. We had to do Re curettage explorative in 7 patients.

Conclusions: $45-50$ years of age is the period of menopause. We recommended theapy IUD with gestagene as more convenient for women.

Keywords: Menorrhagia, IUD, treatment.

\section{5}

VALUATION FULFILLMENT OF PATIENTS DEALT WITH RALOXIFENO AND EFFECTS OF THE THERAPY ON THE ENDOMETRIUM

$\underline{\text { M. Sosa Marrero }}^{1}$, L. Estevez Suárez ${ }^{2}$, L. Galvan Montesdeoca ${ }^{2}$, C. Delgado Godoy $^{2}$, R. Hurtado Rodriguez ${ }^{2} .{ }^{1}$ Maternal-nfantil University Hospital of Canarias-Las Palmas, Gynecology, Telde, Spain; ${ }^{2}$ Maternal-nfantil University Hospital of Canarias-Las Palmas, Gynecology, Las Palmas, Spain

Objectives: analyze the fulfillment of the indicated medication the rate of abandonment and its causes and to determine if the raloxifeno exerts a proliferativa action on the endometrium

Methods: 103 postmenopausicas of 600 interviewed people included themselves in the study, without THS or with a period superior to 6 months without this treatment. The basal visit took place, treatment was indicated with Raloxifenoand Calciovit.Dbeing patient asintomáticas with high osteoporótico risk according to clinical scale.

Results: Of all the patients including we only could finish the study in 72 (69.9\%) with 31 patients to whom it was not possible to be included, of these 22 by abandonment of the treatment by diverse causes emphasizing that 14 did it by not specialized facultative indication and 9 did not go to some of the controls. Them pautó tto with raloxifeno and was come to controls similar to the 6 and 12 months.

The analysis of the collected data sample that do not exist significant differences in the thickness of the line endometrial of the women including in this one study, during the first 6 and 12 months. There was no case of bled genital Conclusions: We can conclude that the high rate of a by medical indication locates to us in the ignorance that continues existing in primary attention of the therapies of the climacteric-menopause and that during this period of time, the therapy with raloxifeno does not cause substantial changes of the endometrium.

Keywords: Endometyum FULFILLMENT raloxifeno

\section{6}

POSTOPERATIVE TACTICS FOR TREATING PATIENTS WITH CLIMACTERIC SYNDROME AND CONNECTIVE TISSUE DYSPLASIA

K. Mylytsya, N. Lutsenko. Medical Academy of Postgraduate Education, Zaporizhzhya, Ukraine

Objectives: The aim of the research is to study the predisposing factors of hernia development with patients with climacteric syndrome and nondifferentiated connective tissue dysplasia and to define the postoperative treatment tactics.

Methods: Surveying and antropometrying 400 surgery clinic patients for the occurance of connective tissue dysplasia (CTD). The phenotypical symptoms have been found with 118 patients, including 42 males and 76 females. 49 female patients with CTD have been diagnosed having climacteric syndrome (CS).

Results: The results of the experimental and clinical - morphologyc research prove the imbalance of collagen formation as well as inhibited aponeurosis cicatrical tissue formation (up to 12 months), followed by its failure during the postoperative treatment in case of CTD. When CTD is accompanied by CS with the characteristic reduction of collagen formation, it leads to inter-hindering influence, which results in hernia development, including the post-operative ones, as well as abdominal circumference increase and formation of pendulous abdomen.

Conclusions: In case of surgical treatment of female patients with CS and CTD to prevent post-operatibe hernia formation and pendulous abdomen, it's necessary to use grid transplant and during the post-operative period it's necessary to give hormones replacement therapy during at least 12 months (unless there are some contraindications).

Keywords: Climacteric syndrome, connective tissue dysplasia, hernia, hormone replacement therapy.

\section{7}

P53 EXPRESSION IS DOWN-REGULATED IN LICHEN SCLEROSUS DURING PIMECROLIMUS (ELIDEL ${ }^{\circledR}$ ) TREATMENT

R. Nissi. Kemi Central Hospital, Kemi, Finland

Objectives: Pimecrolimus cream $1 \%\left(\right.$ Elidel $^{\circledR}$ ) has recently been successfully indicated for inflammatory cutaneus diseases. However, there are no 